Initial Characterization of a Highly

Contaminated High Explosives Outfall in

Preparation for In Situ Bioremediation

Betty A. Strietelmeier

Patrick J. Coyne

Patricia A. Leonard

W. Lamar Miller*

Jerry R. Brian ${ }^{* *}$

*Visiting Professor from Environmental Engineering Sciences,

University of Florida, Gainsoille, Florida 32611

** Visiting Professor from New Mexico Junior College,

Hobbs, New Mexico 88240 


\section{DISCLAIMER}

This report was prepared as an account of work sponsored by an agency of the United States Government. Neither the United States Government nor any agency thereof, nor any of their employees, make any warranty, express or implied, or assumes any legal liability or responsibility for the accuracy, completeness, or usefuiness of any information, apparatus, product, or process disclosed, or represents that its use would not infringe privately owned rights. Reference herein to any specific commercial product, process, or service by trade name, trademark, manufacturer, or otherwise does not necessarily constitute or imply its endorsement, recommendation, or favoring by the United States Government or any agency thereof. The views and opinions of authors expressed herein do not necessarily state or reflect those of the United States Government or any agency thereof. 


\section{DISCLAIMER}

Portions of this document may be illegible in electronic image products. Images are produced from the best available original document. 


\section{CONTENTS}

List of Tables $\quad$ vi

List of Figures $\quad$ vi

ABSTRACT $\quad 1$

INTRODUCTION 1

Aerobic Degradative Mechanisms and Products 4

Anaerobic Degradative Mechanisms and Products 4

General Site History 4

EXPERIMENTAL METHODS

Preliminary System Design $\quad 5$

Preliminary Sampling Plan 6

Planned Extraction and Analysis Procedures $\quad 7$

Sample Preparation $\quad 8$

Modified Extraction, Spot Test and HPLC Methods 8

$\begin{array}{ll}\text { Other Experimental Methods } & 9\end{array}$

$\begin{array}{ll}\text { RESULTS } & 10\end{array}$

Comparison of Extraction Methods 10

Concentrations of HMX in PRS 16-021(c) Matrix 12

Concentrations of RDX in PRS 16-021(c) Matrix 12

Concentrations of TNT in PRS 16-021(c) Matrix 13

Results of Analysis of the "Chunks" 14

Other High Explosives Found 15

RTCA Toxicity Test Results $\quad 15$

$\begin{array}{ll}\text { DISCUSSION } & 15\end{array}$

Importance of Analytical Accuracy $\quad 15$

Concentration Gradients and Heterogeneity $\quad 16$

Potential Effects of the "Chunks" 20

Potential for Success of Bioremediation Method 20

Toxicity of HE Compounds $\quad 20$

$\begin{array}{ll}\text { CONCLUSIONS } & 21\end{array}$

ACKNOWLEDGEMENTS 21

$\begin{array}{ll}\text { REFERENCES } & 21\end{array}$ 


\section{TABLES}

1 Results of extraction using EPA Method 8330 on selected soil samples from the PRS 16-021(c) outfall

2 Results of extraction using the enhanced extraction method on selected soil samples from the PRS 16-260(c) outfall

3 Percentage increase in contaminant concentration when analyzed by the enhanced extraction method vs. Method 8330

4 Concentrations of HE compounds in samples containing consolidated material

5 Toxicity of relevant high explosive compounds by the RTCA toxicity test system

\section{FIGURES}

1 The chemical structure of common secondary high explosives 2

2 HE anaerobic bioremediation system design for the PRS 6 16-021(c) outfall

3 Preliminary sampling matrix for the PRS 16-021(c) outfall 7

$\begin{array}{lll}4 & \text { Results of HMX analysis on samples in matrix } & 12\end{array}$

$\begin{array}{lll}5 & \text { Results of RDX analysis on samples in matrix } & 13\end{array}$

$\begin{array}{lll}6 & \text { Results of TNT analysis on samples in matrix } & 14\end{array}$

$\begin{array}{lll}7 & \text { HMX gradient from sample matrix } & 17\end{array}$

$\begin{array}{lll}8 & \text { RDX gradient from sample matrix } & 18\end{array}$

$\begin{array}{lll}9 & \text { TNT gradient from sample matrix } & 19\end{array}$ 


\title{
Initial Characterization of a Highly Contaminated High Explosives Outfall in Preparation for In Situ Bioremediation
}

\author{
by \\ Betty A. Strietelmeier, Patrick J. Coyne, Patricia A. Leonard, W. Lamar Miller, \\ and Jerry R. Brian
}

\begin{abstract}
In situ bioremediation is a viable, cost-effective treatment for environmental contamination of many kinds. The feasibility of using biological techniques to remediate soils contaminated with high explosives (HE) requires laboratory evaluation before proceeding to a larger scale field operation. Laboratory investigations have been conducted at pilot scale which indicate that an anaerobic process could be successful at reducing levels of $\mathrm{HE}$, primarily HMX, RDX and TNT, in contaminated soils (Young et al., 1994). A field demonstration project has been designed to create an anaerobic environment for the degradation of $\mathrm{HE}$ materials. The first step in this project, initial characterization of the test area, was conducted and is the subject of this report. The levels of $\mathrm{HE}$ compounds found in the samples from the test area were higher than the EPA Method 8330 was able to extract without subsequent re-precipitation; therefore, a new method was developed using a superior extractant system. The test area sampling design was relatively simple as one might expect in an initial characterization. A total of 60 samples were each removed to a depth of 4 inches using a 1 inch diameter corer. The samples were spaced at relatively even intervals across a 20 foot cross-section through the middle of four 7-foot-long adjacent plots which are designed to be part of an in situ bioremediation experiment. Duplicate cores were taken from each location for HE extraction and analysis in order to demonstrate and measure the heterogeneity of the contamination. Each soil sample was air dried and ball-milled to provide a homogeneous solid for extraction and analysis. Several samples had large consolidated pieces of what appeared to be solid HE. These were not ballmilled due to safety concerns, but were dissolved and the solutions were analyzed. The new extraction method was superior in that results obtained for several of the contaminants were up to 20 times those obtained with the EPA extraction method. The results obtained from this study showed that the test area contamination is extremely heterogeneous, and that it contains extremely high levels of the three major contaminants, HMX, RDX and TNT. The potential for success of a bioremediation strategy is discussed.
\end{abstract}

\section{INTRODUCTION}

High explosive (HE), or energetic material, is terminology used to refer to materials more commonly known as propellants, explosives and pyrotechnics. These materials are susceptible to initiation, or self-sustained energy release. Self-sustained energy release is 
initiated when these materials are exposed to stimuli such as heat, shock, friction, chemical incompatibility, or electrical charge. Explosives are classified as primary or secondary based on their susceptibility to initiation. Primary explosives are more sensitive to initiation and are used to initiate secondary explosives. Secondary explosives, which include 2,4,6trinitrotoluene (TNT), cyclo-1,3,5-trimethylene-2,4,6-trinitramine (RDX), octahydro1,3,5,7-tetranitro-1,3,5,7-tetraazocine (HMX) and methyl-2,4,6-trinitrophenylnitramine (tetryl), are much more prevalent at military sites than primary explosives. Secondary explosives can be classified according to their chemical structure as nitroaromatics (e.g. TNT), and nitramines (e.g. RDX and HMX) (Figure 1).
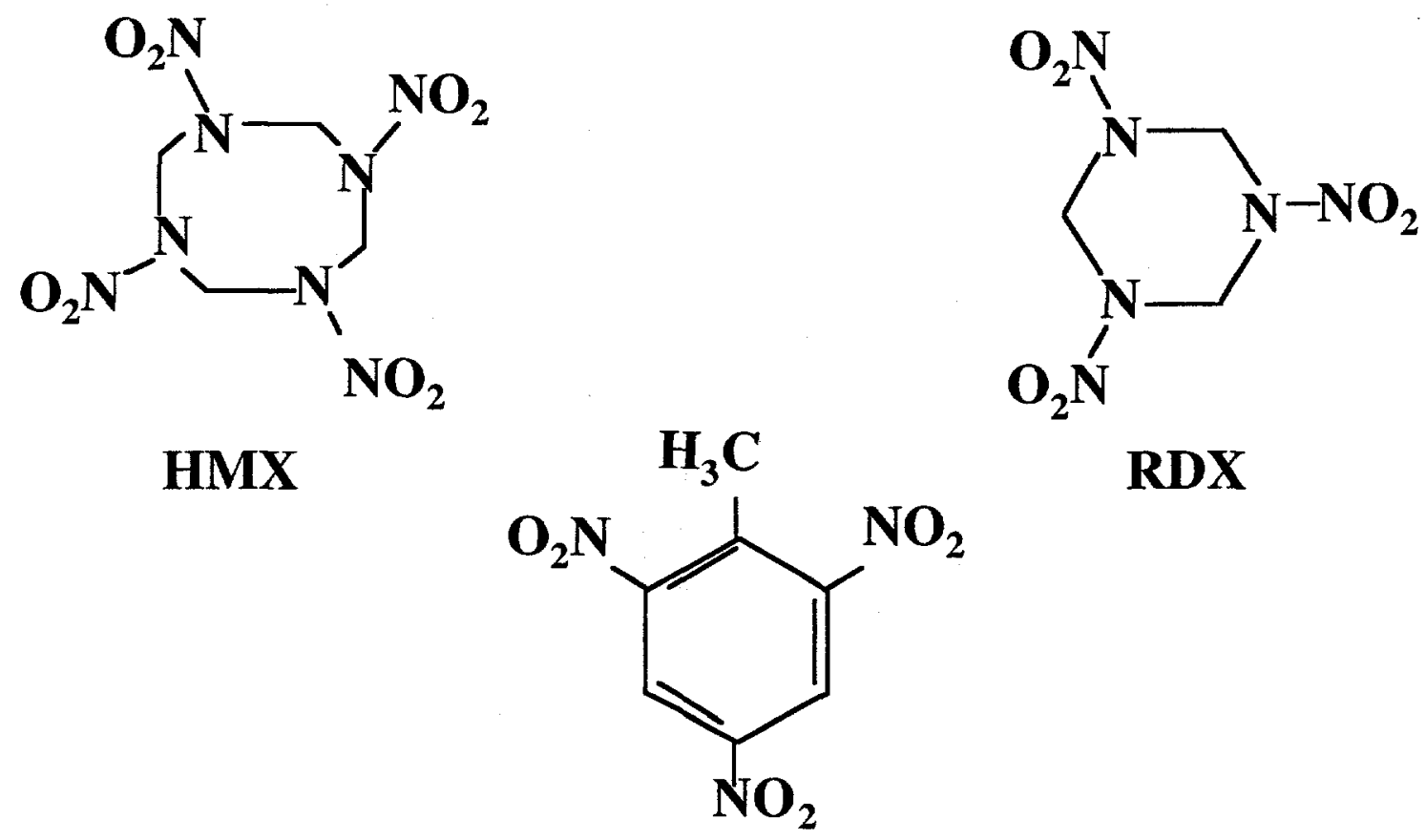

RDX

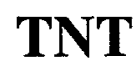

Figure 1. The chemical structure of common secondary high explosives.

The major HE environmental contaminants consist of these two groups, the nitroaromatics and the nitramines. The first group, the most important member of which is TNT, consists of derivatives of toluene that contain the benzene ring structure and various numbers of nitro group substituents. TNT and the di- and mono-nitrotoluenes are the major environmental pollutants. There has been much research time and effort devoted to these compounds, as they are a major problem for military organizations worldwide. Other nitroaromatics that are structurally related to the nitrotoluenes, but tend to be less explosive and toxic, are the nitrophenols, nitrobenzenes, nitroanilines and nitrobenzoates, among others. Much research has been completed in order to elucidate the biodegradative pathways for these compounds, some of which may be applicable to nitrotoluenes, as the pathways used by microorganisms to degrade them may be similar. However, the majority of these related compounds are degraded aerobically and they are much easier to degrade than the more recalcitrant and toxic nitrotoluenes. 
The nitramine group is represented almost exclusively by the two compounds RDX and HMX. There is proportionately less information available on the degradability of these compounds, conducted largely through the Department of Energy (DOE) programs, although these compounds are also heavily utilized by the military for nuclear warhead production and deployment, and research outside the DOE has been initiated. Examples of publications include Binks et al. 1995 and Funk et al. 1993.

Many Department of Defense (DoD) sites are contaminated with explosive wastes as a result of explosives manufacturing; munitions load, assembly, and pack operations; explosives machining, casting, and curing; open burn and open detonation operations; and laboratory testing of munitions, and demilitarization operations. The manufacture of explosives and the cleaning and repacking of old munitions require large quantities of water. During the early years of explosives research, manufacturing and testing, TNT was the major component. Later developments emphasized RDX and HMX. As a result, the wastewater from munitions processing is contaminated with TNT, RDX and HMX. For many years, these waters were discarded outside manufacturing facilities on the ground or in lagoons that leached explosives into soil, groundwater, rivers and lakes. The fate of $\mathrm{HE}$ materials is of concern today not only because of possible initiation hazards in highly contaminated soils, but also because of the toxicity of these materials and their metabolites and the resulting slow, natural degradation rate. Although these materials generally have low water solubilities and sorb strongly to soils, they retain mobility in the subsurface which increases their level of environmental concern.

The use of bioremediation to clean up soils and groundwaters has advanced significantly in the past 10 years, with many research hours and dollars devoted to studying the factors that affect success or failure of any attempt to use it as a remedial technique. It is only recently that the tools have become available for the research scientist to begin to study one of those factors, perhaps the most important one, that is the microbial populations indigenous to the polluted site. The standard microbiology methods of enrichment culture and plate or microscopic counting, while valuable, gave the researcher information on only a tiny subset of the total population present in any given soil. This is because only $0.1-1 \%$ of the organisms present in a gram of soil are capable of being cultured with present-day knowledge and procedures. With the advent of the explosion in molecular biology techniques and instrumentation, it is now becoming possible to answer questions regarding the microbial populations at a given site, such as what effect the bioremediation treatment selected has on them as a whole, and what effect it has on the populations that are actually involved in the degradative process. Other important questions are : 1) what fraction of the population is involved in actually biodegrading the compound(s) present, and 2) are there any organisms present in sufficient numbers to make bioremediation possible, particularly at heavily-contaminated sites where toxicity from the pollutant may play a large role?

The bioremediation of HE is one area that has received much attention in recent years. There is a very large database of studies involving microorganisms that degrade various high explosives and related nitroaromatics, either isolated from soil or groundwater, or from the $\mathrm{HE}$ aqueous processing wastes and sludges. There are two basic sets of environmental conditions under which groups of organisms gain access to the energy stored in HE compounds through bioremediation. These are aerobic- and anaerobic-based metabolic pathways, generally in a co-metabolic fashion, although there are isolated reports of organisms capable of utilizing these compounds as sole carbon, nitrogen and/or energy sources. Within these two major categories of metabolic processes, there appear to be a variety of mechanisms or pathways that have been elucidated by researchers. These mechanisms can be separated based on the intermediates and end-products of the degradation pathway. 


\section{Aerobic Degradative Mechanisms and Products}

Nitroaromatics are degraded through reduction of the nitro groups by a series of nitroreductase enzymes that appear to be quite specific, although co-metabolism does occur in many cases. Aerobic nitroreductases are oxygen-insensitive whereas anaerobic enzymes are oxygen-sensitive (Bryant and DeLuca, 1991). The initial steps in both of these aerobic and anaerobic pathways involve reduction of the nitro groups to a series of intermediate compounds, from nitroso- and hydroxylamino-based intermediates to amino-substituted aromatics (McCormick et al., 1976; Kinouchi and Ohnishi, 1983; Schackmann and Müller, 1991). The aerobic pathway generally produces only TNT intermediates through the mononitro-diamino compounds, with anaerobic conditions required for reduction to triaminotoluene (TAT). Also, aerobic pathways result in formation of azoxy polymers formed through condensation of nitroso intermediates under aerobic conditions. Vorbeck et al. (1994) also isolated a transient hydride-Meisenheimer complex product from TNT degradation under aerobic conditions. The other major aerobic degradative mechanism involves direct removal of the nitro group as nitrite (Spain et al., 1979; Zeyer and Kearney, 1984; Bruhn et al., 1987). An alternative oxidative pathway which resulted in nitrotoluene degradation at the toluene methyl group to benzyl alcohol, then benzaldehyde and finally to benzoate was engineered in a Pseudomonas species by introduction of the TOL plasmid from Ps. putida (Delgado et al., 1992).

Nitramines are degraded largely anaerobically, however, a recent report by Binks et al. (1995) showed that RDX can be degraded aerobically under nitrogen-limiting conditions where the organism uses the RDX as a nitrogen source. Aerobic degradation of HMX has not been reported. Fungi capable of degrading lignin-based compounds have been shown to degrade both nitroaromatics and nitramines aerobically (Spiker et al., 1992; Sublette et al., 1992; Valli et al., 1992; Stahl and Aust, 1993a, b).

\section{Anaerobic Degradative Mechanisms and Products}

As stated above, nitroaromatics are degraded anaerobically through a reductive process where the nitro groups are successively reduced through nitroso- and hydroxylaminointermediates to amino groups. The final reduction product under anaerobic conditions is triaminotoluene (TAT) which tends to accumulate in soil. TAT sorbs strongly to soil and is difficult to extract and measure, also becoming resistant to further degradation. The opening of the aromatic ring and complete mineralization has been reported to occur, however it appears to result in only minor amounts of mineralization of TNT.

The anaerobic reduction of the nitro groups of the nitramines RDX and HMX appears to be the major degradative pathway for these HEs. Nitroso intermediates have been identified (McCormick et al., 1976) and complete mineralization occurs, however all of the intermediate compounds have not been identified as they disappear rapidly from the soil, or become strongly sorbed and are no longer extractable, or readily available for further degradation.

\section{General Site History}

TA-16 is located in the southwest corner of the Laboratory property. It contains 2,410 acres or 3.8 square miles. The land is a portion of that acquired by the Department of the Army for the Manhattan Project in 1943. It was used prehistorically by the ancestral Indians of the Pajarito Plateau and prior to World War II for farming and a sawmill operation. TA-16 is bordered by Bandelier National Monument along State Road 4 to the 
south and the Santa Fe National Forest along State Road 501 to the west. To the north and east, it is bordered by TAs $8,9,14,15$, and 49 . TA-16 is fenced and posted along State Road 4. Water Canyon, a 200-ft-deep ravine with steep walls, separates State Road 4 from active sites at TA-16. Canon de Valle forms the northern border of TA-16. Security fences surround the production facilities.

TA-16 was established to develop explosive formulations, cast and machine explosive charges, and assemble and test explosive components for the US nuclear weapons program. Almost all of the work was conducted in support of the development, testing, and production of explosive charges for the implosion system. Present day use of this site is essentially unchanged, although facilities have been upgraded and expanded as explosive and manufacturing technologies advanced.

TA-16-260 is located on the north side of TA-16. The current structure was originally built in 1951, with minor modifications to the structure made later. It is a HE machining facility that processes large quantities of explosives. Machine turnings and HE washwater are routed to the 13 sumps as waste which drains into the outfall. The drainage channel from the outfall is contaminated with high-explosive wastes and barium (from baritol disposal). The outfall has been deactivated, and it is still permitted as (EPA) 05A056. The sumps, drain lines, and troughs have been designated PRS 16-003(k) and the outfall as PRS 16021(c).

The "RFI Report for Potential Release Sites in TA-16" [PRSs 16-003(k) \& 16-021(c)] dated September 1996 indicates that Phase 1 sampling was completed during FY 1995. Sampling and analysis was designed to determine the existence, concentrations, and migration pathways of $\mathrm{HE}$, inorganics, volatile organic compounds (VOCs), semivolatile organic compounds (SVOCs) and uranium. The results of the sampling and analysis revealed that the outfall associated with TA-16-260 contained contamination levels of $\mathrm{HE}$, namely HMX and RDX, above the Screening Action Levels (SALs) for a distance of $600 \mathrm{ft}$ from the outfall.

The RFI report included only two samples near the TA-16-260 outfall area designated "the pond" that was selected for in situ remediation testing. Because of this lack of substantive data, the initial step in the project included an extensive sampling of the test area prior to initiation of the experiment. The results of the sampling and analysis of this area are the subject of this report.

\section{EXPERIMENTAL METHODS}

\section{Preliminary System Design}

Seven specific problems had to be overcome by our system design: 1) the effective distribution of moisture to create an anaerobic environment for $\mathrm{HE}$ degradation, 2) establishment and maintenance of uniform moisture saturation to reduce any hazard of detonation or explosion, 3) maintenance of proper moisture levels to prevent leaching or surface runoff, 4) effective distribution of nutrients to enhance microbial propagation, 5) non-hazardous sampling methods in a "spark sensitive" environment, 6) establishment of a sampling plan to minimize effects of sample heterogeneity and/or contaminant concentration gradient on experimental results, and 7) dispersion of anaerobic gases generated during microbial metabolism.

The system was designed to be located at the outfall area TA-16-260 [PRS 16-021(c)] at four designated HE-contaminated soil test plots each 7 ' $\times 20^{\prime}$. An electronically controlled 
water distribution system consisting of 1 " PVC pipe manifolds, drip irrigation/fertigation control boxes and valves, irrometers, polypipe, and drip lines was installed. Plots were designed to be covered with plastic sheeting (HDPE, $20 \mathrm{mil}$ ), and sandbags were to be used to hold the cover in place. A nonpotable water source from the back of building 260 was to be utilized for providing water to the site. Moisture meters would be positioned to monitor moisture retention levels to maintain a soil field saturation capacity of $80 \%$ to avoid discharge conditions. System design and strategic positioning of valves would allow flexibility in moisture and nutrient addition to each plot on an "as needed" basis. Drip lines would be used as a water/nutrient applicator in conjunction with a "Geo-Textile" soaker mat to provide uniform dispersion of gases generated by the biological activity. Each plot would be covered first by the designated food source, soaker mat, drip lines, and a layer of HDPE (Figure 2), anchored with sand bags.

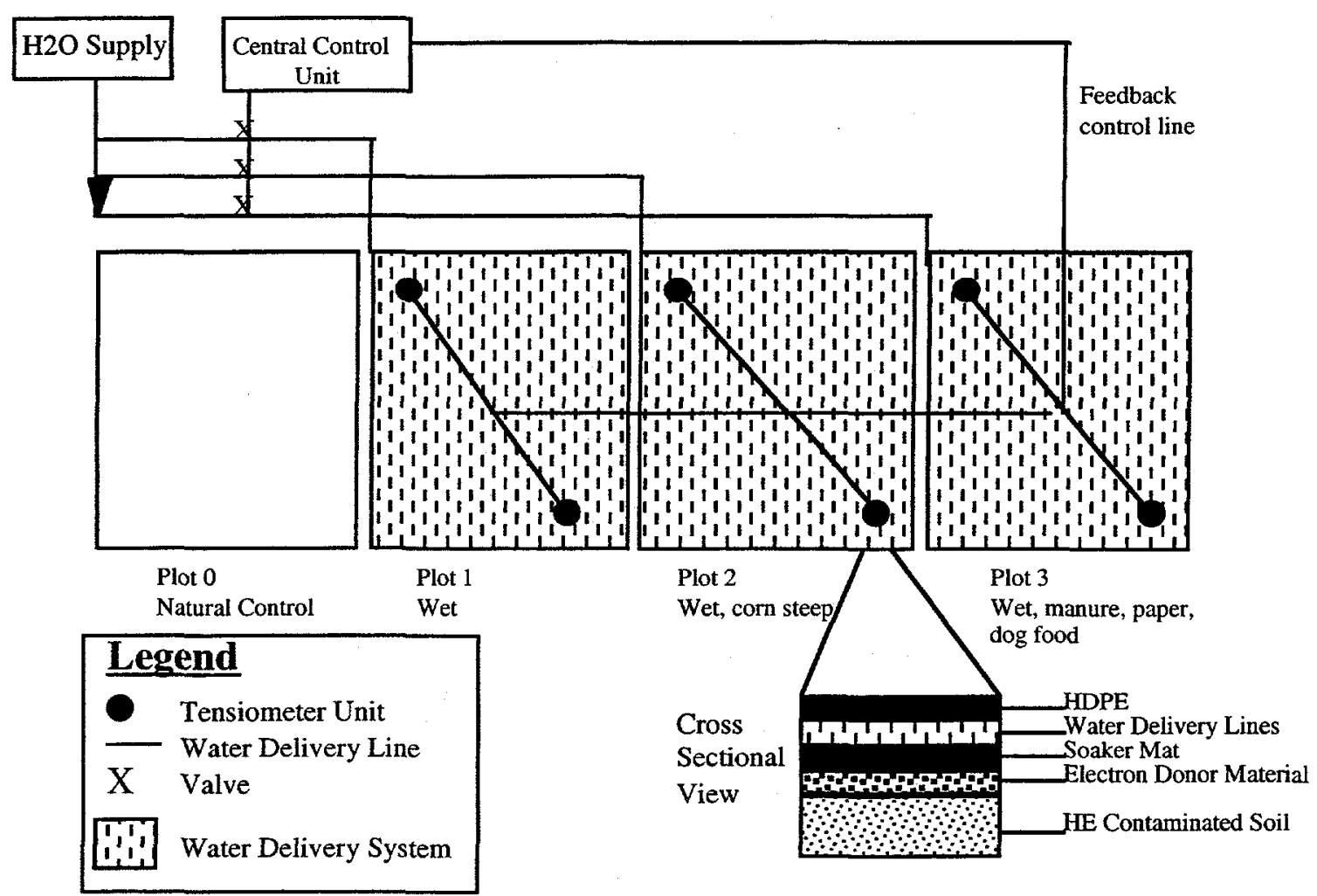

Figure 2. HE anaerobic bioremediation system design for the PRS 16021(c) outfall.

\section{Preliminary Sampling Plan}

Prior to starting the bioremediation experiment, a modified transect surface sampling of soil was conducted utilizing cores of soil 1" in diameter by 4 " in depth. Collection at five sampling points (in triplicate) from each plot across the approximate center of the plot was carried out on September 12, 1997. Two samples to determine contaminant HE concentrations, and one sample to determine microbial populations were collected and placed in sealed sample bags which were immediately taken to the HE laboratory and placed under refrigeration. Samples were labeled by sampling date $(09127, \mathrm{~mm} / \mathrm{dd} / \mathrm{y})$, plot number $(0-3)$, sample (A-E), replicate $(1,2)$ and section (top or bottom) of the 4 inch core 
for microbial samples (T,B). The preliminary sampling matrix is shown in Figure 3.

Following initiation of the experiment, monthly collection of duplicate samples from three sampling points following the initiation of the bioremediation experiment was planned, one sample to determine $\mathrm{HE}$ concentrations, and one sample to determine microbial populations. The final sampling location and experimental matrix was dependent on the distribution and heterogeneity of the contamination as determined from the initial set of samples, and will be determined after consultation with appropriate statistical staff in the Environmental Remediation (ER) project office.

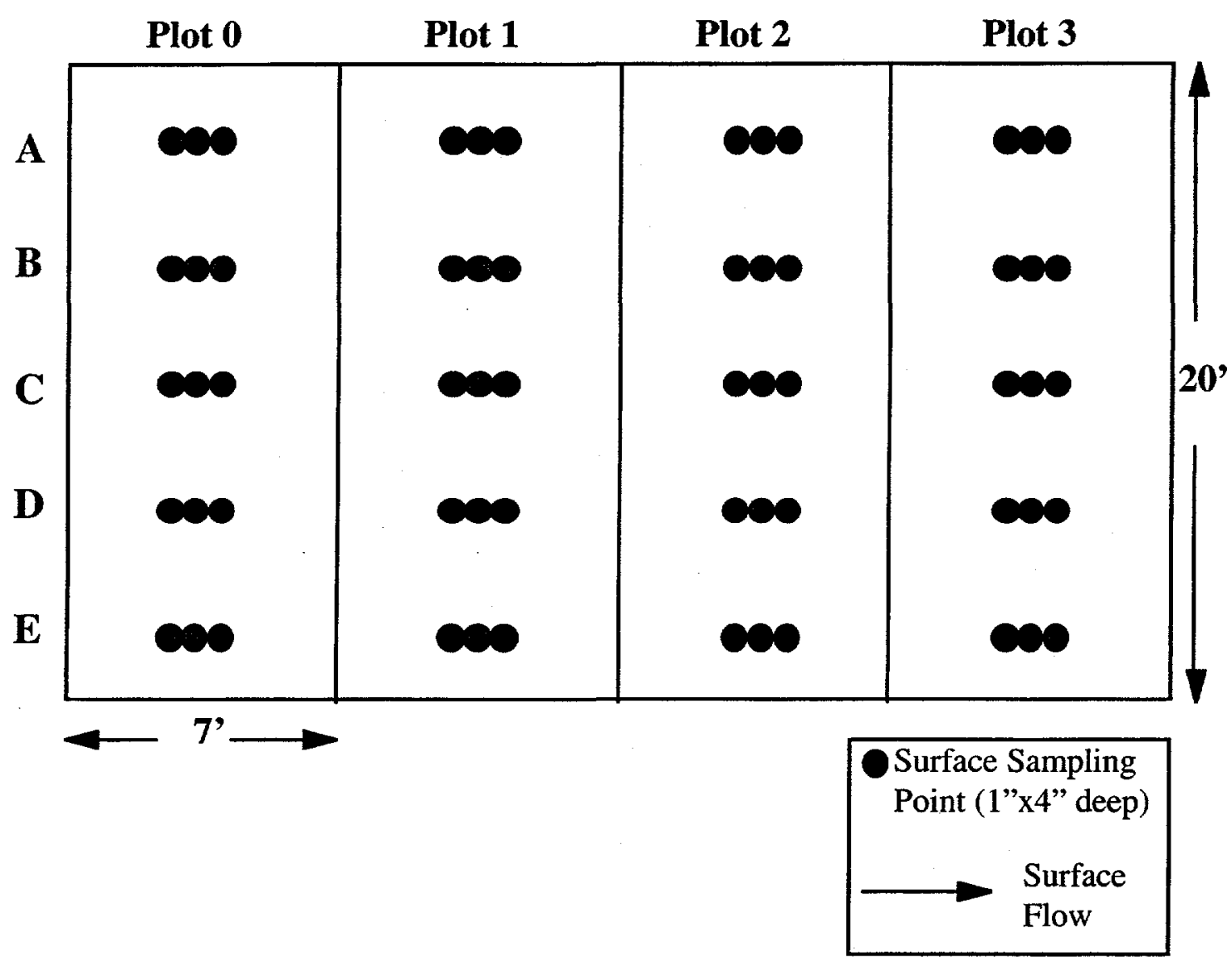

Figure 3. Preliminary sampling matrix for the PRS 16-021(c) outfall.

\section{Planned Extraction and Analysis Procedures}

The goal of the remediation project was the reduction of total levels of nitoaromatic (TNT) and nitramine compounds (HMX and RDX) to below 5\% in order to allow for excavation and further treatment. Concentrations of high explosives were determined in the initial set of soil samples. Quantitative analysis for the parent explosives and their metabolites was conducted according to the EPA Method 8330 which utilized acetonitrile extraction, sonication and analysis by high performance liquid chromatography (HPLC).

Other analyses planned included chemical analysis to determine amounts of nitrate and ammonia produced, as well as $\mathrm{pH}$ and other field methods as may be determined to be 
appropriate. Nitrate was included as it is important that carcinogenic nitrosamines are not generated in the soils. It is, however, extremely unlikely that any free nitrate will be released by microbial processes in the soil as denitrification is likely to be the predominant degradation process. Ammonia measurements were planned as an indicator of microbial conversion. $\mathrm{pH}$ changes in the surface water, collected in tensiometers, will be determined once nutrient amendments have been initiated.

Bacterial studies planned included extraction for enumeration from soil samples using a method based on one employed by McCarthy and Murray (1996). Microbial populations would be followed over time by three methods: viable counts, denitrifying MPNs, and direct counts. Total numbers of aerobic, heterotrophic bacteria would be determined either by a most probable numbers method (Harrigan, 1976) or by plate counting. Direct counts of bacteria would be determined by means of fluorescent staining with 4,6-diamidino-2phenylindole (DAPI). DAPI is a DNA-specific stain that is superior to other stains in instances of high background fluorescence. The method used for DAPI staining is based on an optimized method for direct counting of soil microorganisms (Yu et al., 1995). Nitrate-reducing bacteria would be determined by another MPN method that has been used successfully for enumeration (Tiedje, 1982).

\section{Sample Preparation}

Each sample was individually photographed and catalogued in order to show the distribution of the $\mathrm{HE}$, and to document the presence of any solid chunks of HE in the samples. The samples were then broken up, wet weights obtained, and the samples were allowed to air-dry at room temperature for 24 hours without exposure to sunlight, dry weights were obtained, then each sample was ball-milled to provide a homogeneous sample. Several samples contained consolidated material which was thought to be "chunks" of explosive. Spot testing demonstrated that a qualitatively large amount of $\mathrm{HE}$ was present in these samples. These particular samples (total of 6) were air dried, then the whole sample was extracted and used for the analysis without preliminary ball-mill treatment.

\section{Modified Extraction, Spot Test and HPLC Methods}

A subset of the initial set of samples was extracted by EPA Method 8330 in order to optimize the procedures used. During performance of this analytical procedure, it was noticed that certain samples contained crystals of an unknown material in the extract following addition of an aqueous calcium chloride solution that is designed to flocculate clay materials and cause them to settle more rapidly. We determined that the crystals were approximately 50:50 HMX:RDX, indicating that the contaminants were present in concentrations that exceeded the solubility of this organic-aqueous phase. We were concerned that such high concentrations might also exceed the solubility of the HMX and RDX in the acetonitrile extractant, so we developed a new extractant that consisted of $50 \%$ acetonitrile and 50\% dimethyl sulfoxide (DMSO). This extractant was tested on the same subset of samples and the results confirmed our hypothesis that the EPA method was not extracting all of the HMX/RDX. The use of this extraction system necessitated development of a new HPLC gradient method in order to avoid any artifacts from the DMSO in the sample. 
Brief descriptions of the new methods follow:

\section{Extraction}

The extraction follows the Method 8330 procedure with the following modification to the method parameters. The extractant solution consists of 50\% acetonitrile:50\% DMSO (8330 uses $100 \%$ acetonitrile), the soil amount used is $2 \mathrm{~g}$ with a $10 \mathrm{ml}$ volume of extractant solution added. The sonication time and temperature are 1 hour and $20^{\circ} \mathrm{C}$.

\section{HE Spot Tests}

Prior to extraction, we performed a spot test on a small sub-sample of the soil using the LANL DX-2 Spot Test Kit for HE--a colorimetric, qualitative analysis kit that has a lower detection limit of $\sim 100 \mathrm{ppm}$ total HE. If a sample tested positive with the kit prior to extraction, the extract was tested following extraction, subjected to dilution (1:10) with acetonitrile, tested again and then was diluted again, if necessary until the total HE was under $100 \mathrm{ppm}$. In this manner, a dilution of the extract was obtained which was then subjected to the calcium chloride treatment according to Method 8330, and transported to the HPLC laboratory for analysis. Both this extract, plus the next higher concentration sample were analyzed and the results compared for accuracy. In general, only 2-3 dilutions were necessary to obtain samples within the analytical range for the HPLC analysis.

\section{Modified HPLC Analysis}

The Method 8330 HPLC analysis is isocratic (uses a single composition and flow rate) using 50\% methanol:water. Our modification uses a gradient procedure with a methanol concentration ranging from 15 to $55 \%$. The method has comparable resolution and detection of all compounds analyzed by Method 8330 (resolution of nitrotoluenes remains a problem as with Method 8330). The gradient procedure is necessary because of the DMSO contained in the sample extract.

\section{Other Experimental Methods}

\section{Toxicity Assay}

A method for testing the toxicity of chemical compounds has been developed by Dr. James Botsford of the New Mexico State University Biology Department (Botsford 1998; Botsford 1998, submitted). This method, called the Rhizobium toxic chemical assay (RTCA) system was used to examine the toxicity of several HE compounds. The toxicity of soil samples in comparison to these standard compounds will also be tested using this method.

\section{Microorganism Extraction}

Although no HE-contaminated soils were examined, surrogate soils were used in method development resulting in the procedure described. Each soil sample was broken up and thoroughly mixed. Rocks and organic debris were removed, then $10 \mathrm{~g}$ was weighed out and placed in a Waring blender with $90 \mathrm{ml}$ of sterile saline ( $\mathrm{pH}$ 7.0) to produce a 1:10 dilution of the original sample (a separate $\sim 2 \mathrm{~g}$ weighed sub-sample was oven-dried and reweighed to determine the dry weight of the sample). The sample was then blended three times on low speed for 30 seconds, with icing of the container for 30 seconds between 
blending steps. Following the last blending, a timer was set for 10 seconds, at the end of which time a $0.5 \mathrm{ml}$ sample was taken from $\sim 0.5$ inch below the surface of the supernatant. This sample was serially diluted 1 million-fold to produce a series of dilutions for direct, viable and MPN counting. Each extraction removes approximately $10 \%$ of the population of microorganisms contained in the original sample. While this method is technique dependent, it results in a reasonable estimate of the microbial population and can be used to make qualitative comparisons from sample to sample.

\section{$\underline{\text { Direct Counts }}$}

Total bacterial counts were obtained from the same surrogate soils by staining of the cell DNA with DAPI, a fluorescent dye which is detected using an epifluorescence microscope. Two different dilutions of the extract are used in the procedure and the results are compared. The slides with the most reasonable number of organisms is used to enumerate the bacteria. The results obtained are the total number of cells (both viable and nonviable) contained in the original sample.

\section{Other Microbial Counting Procedures}

Viable counts and MPN methods for aerobic, denitrifying and sulfate reducing bacteria were developed, but the project was suspended before any results were obtained, therefore the methods are not reported here.

\section{RESULTS}

\section{Comparison of Extraction Methods}

A selection of samples from different locations within the remediation area were extracted using EPA Method 8330, as well as using our modified extraction and analysis method. Both sets of samples were analyzed for the major HE components (i.e. TNT, RDX and HMX) using the respective HPLC method and the results are presented in Tables 1 and 2 below.

TABLE 1. Results of extraction using EPA Method 8330 on selected soil samples from the PRS 16-021(c) outfall.

\begin{tabular}{|c|c|c|c|}
\hline Sample Number & HMX, ppm & RDX, ppm & TNT, ppm \\
\hline OA1 & 89.4 & 3.5 & 0.7 \\
\hline 0A2 & 50.7 & 3.9 & 1.7 \\
\hline 0E1 & 23.9 & 9.4 & 0.0 \\
\hline 0E2 & 83.1 & 11.3 & 1.3 \\
\hline 1B1 & 11388 & 25704 & 16300 \\
\hline 1B2 & 8088 & 21021 & 10293 \\
\hline 2C1 & 6572 & 11197 & 190 \\
\hline 2C2 & 6298 & 24877 & 707 \\
\hline 3D1 & 7455 & 21053 & 6232 \\
\hline 3D2 & 7064 & 14898 & 2940 \\
\hline
\end{tabular}


TABLE 2. Results of extraction using the enhanced extraction method on selected soil samples from the PRS 16-260(c) outfall.

\begin{tabular}{|c|c|c|c|}
\hline Sample Number & HMX, ppm & RDX, ppm & TNT, ppm \\
\hline 0A1 & 260 & 11 & 0.0 \\
\hline 0A2 & 143 & 11 & 0.0 \\
\hline 0E1 & 71 & 17 & 0.0 \\
\hline 0E2 & 260 & 22 & 0.0 \\
\hline 1B1 & 133697 & 122020 & 43144 \\
\hline 1B2 & 172578 & 187683 & 68465 \\
\hline 2C1 & 93808 & 21041 & 470 \\
\hline 2C2 & 123436 & 55794 & 4195 \\
\hline 3D1 & 155359 & 113176 & 23041 \\
\hline 3D2 & 81618 & 31587 & 7191 \\
\hline
\end{tabular}

The enhanced method removed much more of all three of the major HE components from the soils that were contaminated at high levels, particularly so for HMX, which had been observed to be crystallizing out of solution in the Method 8330 upon addition of the aqueous calcium chloride solution. Table 3 shows the percentage increase in the analytical result for the enhanced method over the original Method 8330.

TABLE 3. Percentage increase in contaminant concentration when analyzed by the enhanced extraction method vs. Method 8330 .

\begin{tabular}{|c|c|c|c|}
\hline Sample Number & HMX & RDX & TNT \\
\hline 0A1 & 290 & 310 & N/A \\
\hline 0A2 & 282 & 281 & N/A \\
\hline 0E1 & 297 & 180 & N/A \\
\hline 0E2 & 312 & 196 & N/A \\
\hline 1B1 & 1174 & 475 & 265 \\
\hline 1B2 & 2134 & 893 & 665 \\
\hline 2C1 & 1427 & 188 & 248 \\
\hline 2C2 & 1960 & 224 & 593 \\
\hline 3D1 & 2084 & 538 & 370 \\
\hline 3D2 & 1155 & 212 & 245 \\
\hline
\end{tabular}

Our results indicate that at both high and low levels of HMX and RDX, the enhanced method is superior to the existing EPA method. At low levels of TNT, there is little difference between the two methods, however, at high levels, the enhanced extraction method is again superior. Based on this preliminary study, we chose to use the modified extraction method for the analysis of the full sample matrix. Those results are presented below for each of the three major HE contaminants. 


\section{Concentrations of HMX in PRS 16-021(c) Matrix}

Figure 4 is a three-dimensional graph of the $\mathrm{HMX}$ results obtained for each of the samples from the PRS 16-021(c) outfall. The results are plotted by experimental plot $(0,1,2,3)$ and by transectional sample (A, B, C, D, E) across the area. Duplicate samples were analyzed and plotted separately in order to show heterogeneity. Results are reported as weight percent HE instead of ppm. The conversion factor is $1 \mathrm{wt} . \%=10,000 \mathrm{ppm}$.

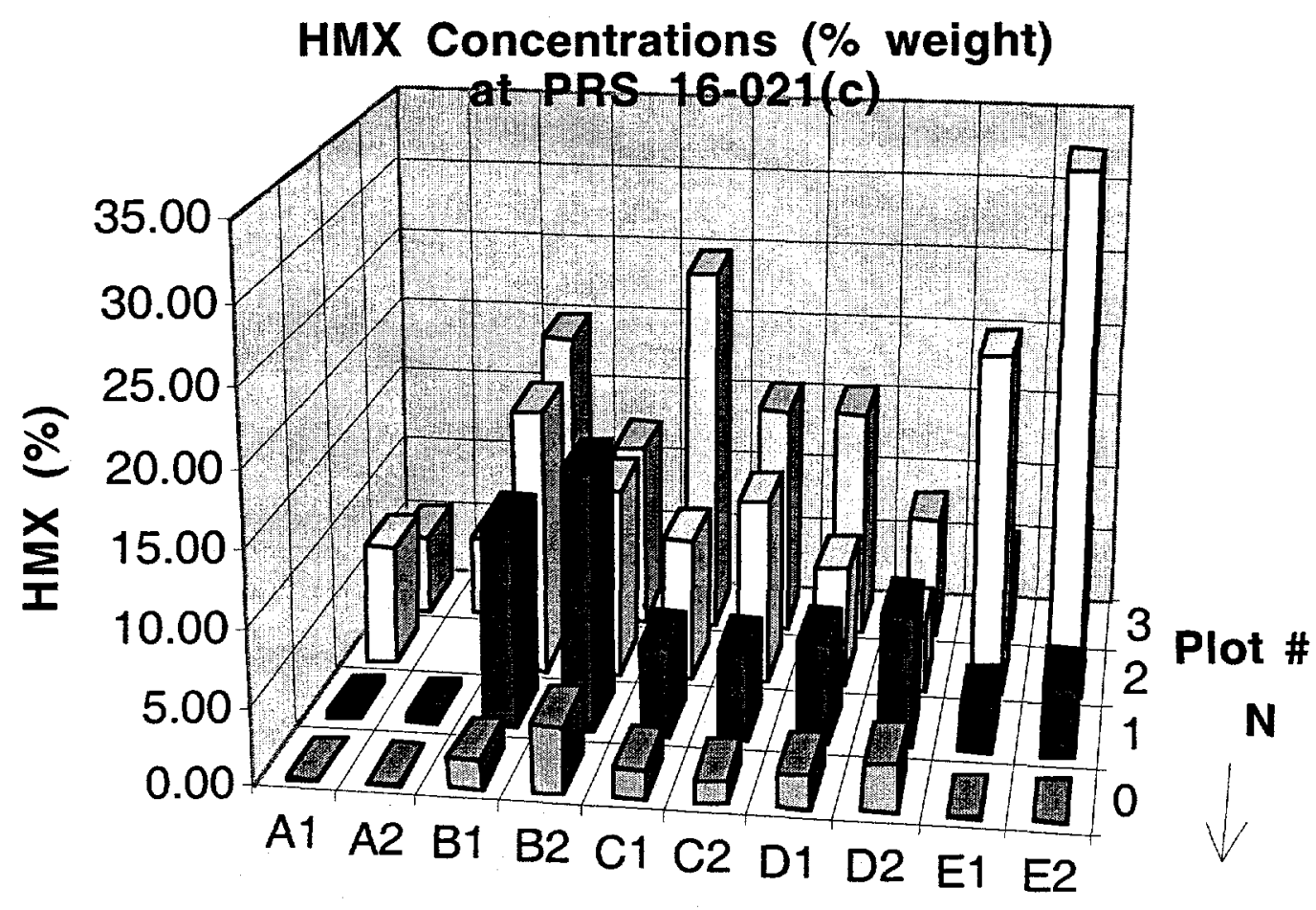

Series and Replicate

Figure 4. Results of HMX analysis on samples in matrix. 1 wt. $\%=$ 10,000 ppm.

Concentrations of RDX in PRS 16-021(c) Matrix

Figure 5 is a three-dimensional graph of the RDX results obtained for each sample. The results are plotted as for the HMX data. 


\section{RDX Concentrations (weight \%)}

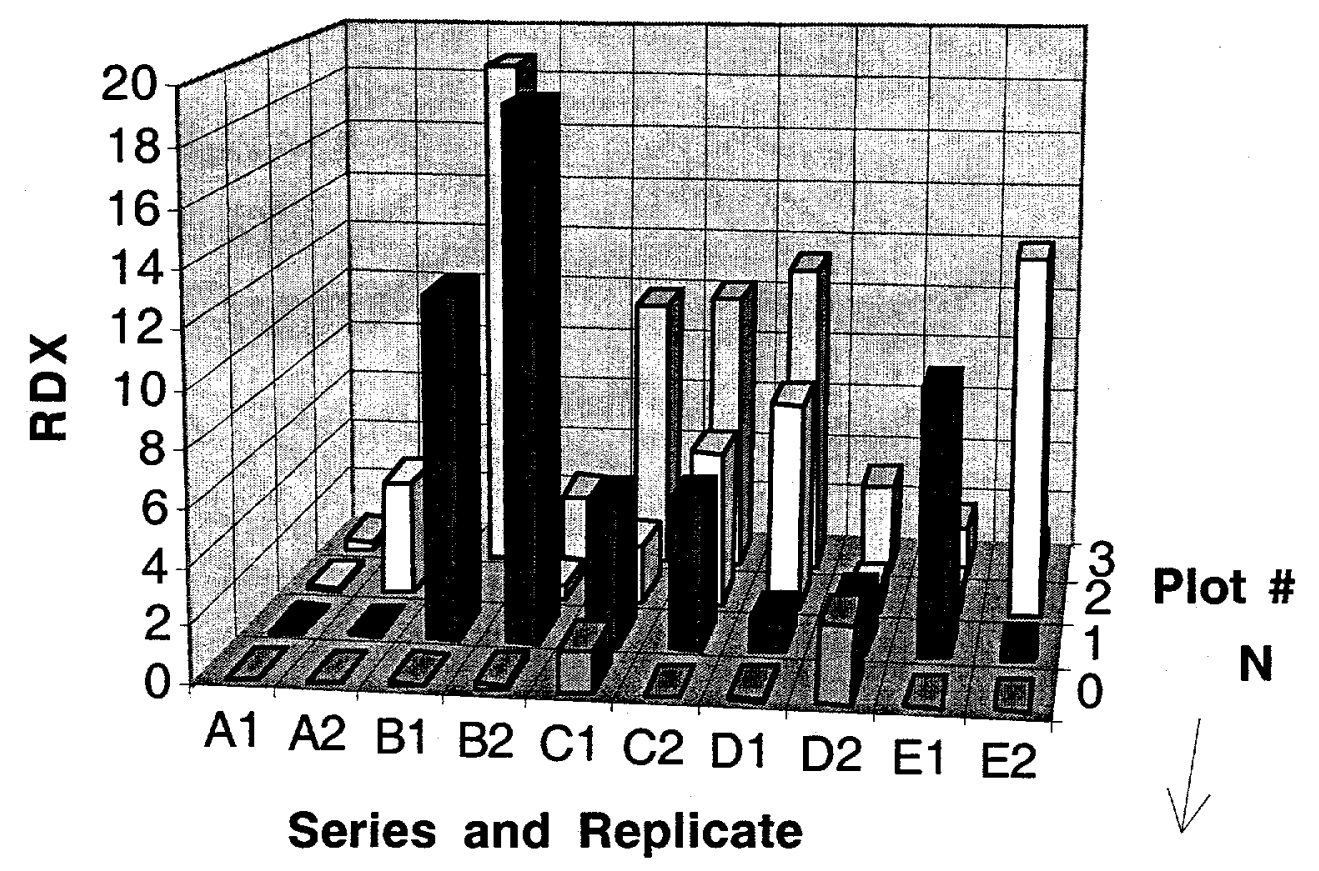

Figure 5. Results of RDX analysis on samples in matrix. 1 wt. $\%=$ 10,000 ppm.

Concentrations of TNT in PRS 16-021(c) Matrix

Similarly, Figure 6 is a graph of the TNT results. 


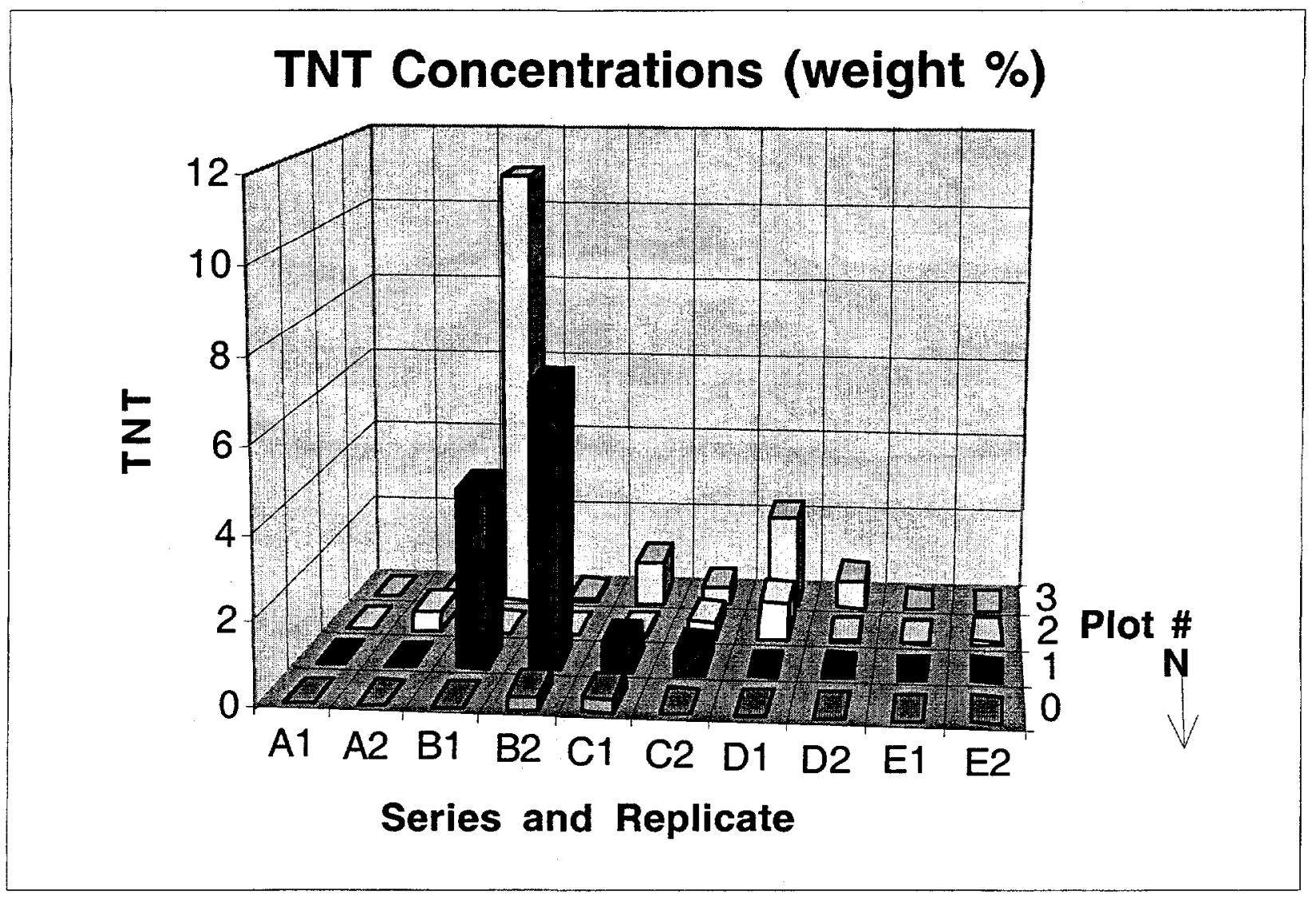

Figure 6. Results of TNT analysis on samples in matrix. 1 wt. $\%=$ 10,000 ppm.

\section{Results of Analysis of the "Chunks"}

The data for the six consolidated samples are presented in Table 4. These sample results are in general agreement (as can be seen in Figures 4-6) with other concentration results from analysis of samples in the matrix taken in close proximity to those containing consolidated material. The results are certainly not as high as one might expect if the consolidated material was pure HE. This result was unexpected and we plan to determine what these consolidated materials are through an alternate analytical procedure.

TABLE 4. Concentrations of HE compounds in samples containing consolidated material.

\begin{tabular}{|c|c|c|c|}
\hline Sample Number & HMX, ppm & RDX, ppm & TNT, ppm \\
\hline 1A1 & 3294 & 28 & 8 \\
\hline 1A2 & 3930 & 210 & 0 \\
\hline 1E1 & 31653 & 93737 & 0 \\
\hline 1E2 & 46772 & 3152 & 0 \\
\hline 3E1 & 53010 & 16515 & 0 \\
\hline 3E2 & 68770 & 7971 & 0 \\
\hline
\end{tabular}




\section{Other High Explosives Found}

In addition to the three primary contaminants, low levels of 2,4-dinitrotoluene and 2,6dinitrotoluene were noted in several samples. The magnitude of the concentrations of the three main HE compounds made it almost impossible to detect any of the other explosives present due to the large dilution factors necessary to bring the concentrations into the analytical range of the HPLC method. Likewise, detection of any of the microbial metabolites, such as the monoamino- and diamino-toluenes was equally difficult. We did detect some of these compounds in some samples, estimated at less than $14 \mathrm{ppm}$ total DNT.

\section{RTCA Toxicity Test Results}

The Rhizobium toxic chemical assay (RTCA) system was used to test the toxicity of TNT, RDX, HMX, 4-amino-2,6-dinitrophenol, 2,4-dinitrotoluene, and 2,6-dinitrotoluene.

Table 5 lists the results obtained for these compounds.

TABLE 5. Toxicity of relevant high explosive compounds by the RTCA toxicity test system.

\begin{tabular}{|l|l|}
\hline Explosive Compound & EC-50 (ppm) \\
\hline TNT & 150 \\
\hline RDX & 674 \\
\hline HMX & 225 \\
\hline 2,4-dinitrotoluene & 238 \\
\hline 2,6-dinitrotoluene & 298 \\
\hline 4-amino-2,6-dinitrophenol & 194 \\
\hline
\end{tabular}

The $\mathrm{EC}_{50}$ is defined as the point at which a $50 \%$ decrease in metabolism of the microorganism (as indicated by dye reduction) occurs as a result of exposure to the toxic compound, and is considered a standard toxicological measure of chemical toxicity.

\section{DISCUSSION}

\section{Importance of Analytical Accuracy}

Most HE-contaminated sites in the environment contain low levels and the HE tends to be difficult to extract due to a tight association with organic matter (humus). The EPA Method 8330 was developed for this type of sample and includes a relatively long sonication period and a solvent suitable for dissolution of the low amounts of HE present. The site we plan 
to remediate is completely different from most sites. The HE concentrations are high enough to be potentially explosive, and the soil has a relatively low organic carbon content, making it less difficult to extract the $\mathrm{HE}$. At a site such as this, it is extremely important to be certain that all of the HE has been extracted in order to avoid underestimation of the amount of contamination. With such high concentrations, the extract needs to be diluted many-fold in order to reach the analytical range of the HPLC method, thus introducing greater error into the final result.

We decided to investigate development of the new method because we were using the Method 8330 to analyze samples at much higher levels than the method was originally designed to analyze. We selected DMSO as a co-solvent because of the excellent solubility of HMX in this solvent, which is routinely used in the explosives industry for this purpose. The presence of DMSO, and the high concentrations of HE made it feasible to reduce the amount of sonication time to a much shorter period. Both of these modifications resulted in a much simpler, shorter extraction method, that helped improve the accuracy and quality of our results. The use of a gradient method on the HPLC instead of an isocratic method does not add greatly to the complexity of the final analytical method.

We analyzed duplicate samples of soil from each sample location following homogenization, and monitored the variation between these duplicates. The precision of the duplicates was generally less than $10 \%$. However, we sampled duplicate cores side by side, and the variation between these cores was significantly greater, sometimes in excess of $100 \%$. This shows that the contamination in the area is extremely heterogeneous.

\section{Concentration Gradients and Heterogeneity}

One of the goals of the project was to sample the outfall and experimental area in a matrix pattern in order to show the level of heterogeneity and to show if there was a concentration gradient in the downhill direction of the outfall. We have graphed the results in order to show the results of the analyses in terms of a potential gradient. The graphs are shown in Figures 7-9. 


\section{HMX Trend (down gradient)*}

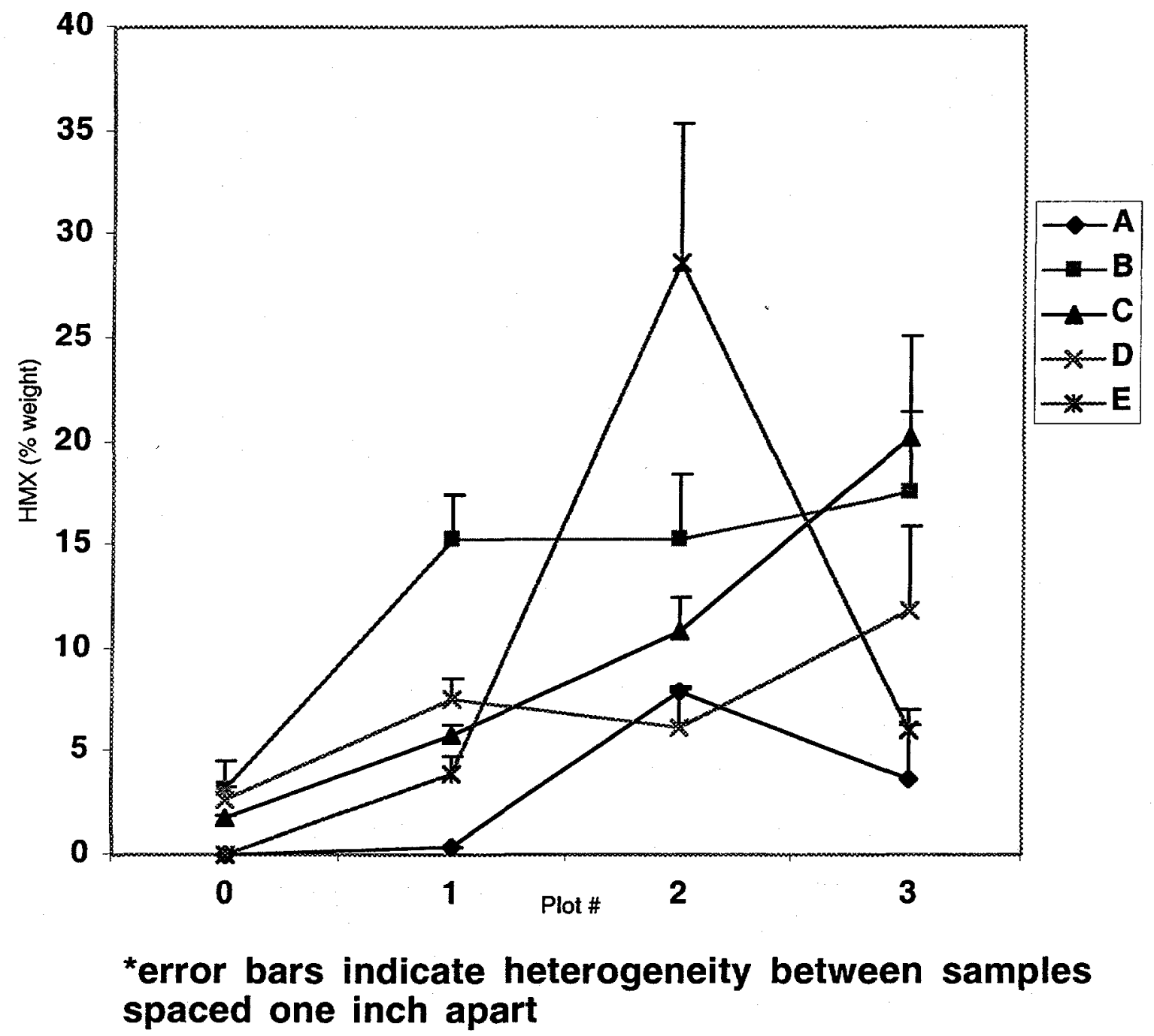

Figure 7. HMX gradient from sample matrix, plot 0 is at head of outfall, highest point, plot 3 is lowest. Samples $A$ through $E$ are approximately equidistant in a perpendicular line across the outfall. 
RDX Trend (down gradient)*

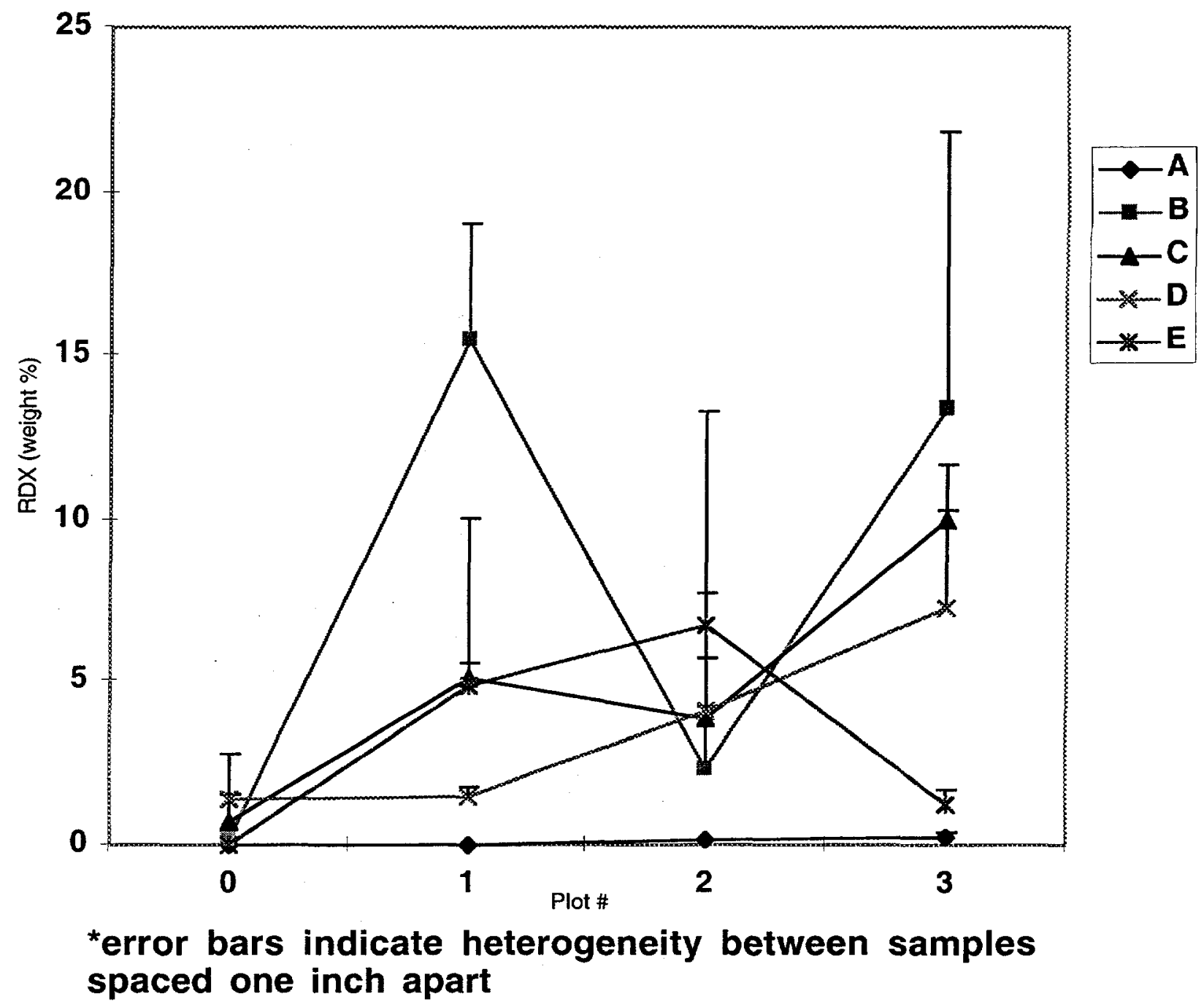

Figure 8. RDX gradient from sample matrix, plot 0 is at head of outfall, highest point, plot 3 is lowest. Samples $A$ through $E$ are approximately equidistant in a perpendicular line across the outfall. 
TNT Trend (down gradient)*

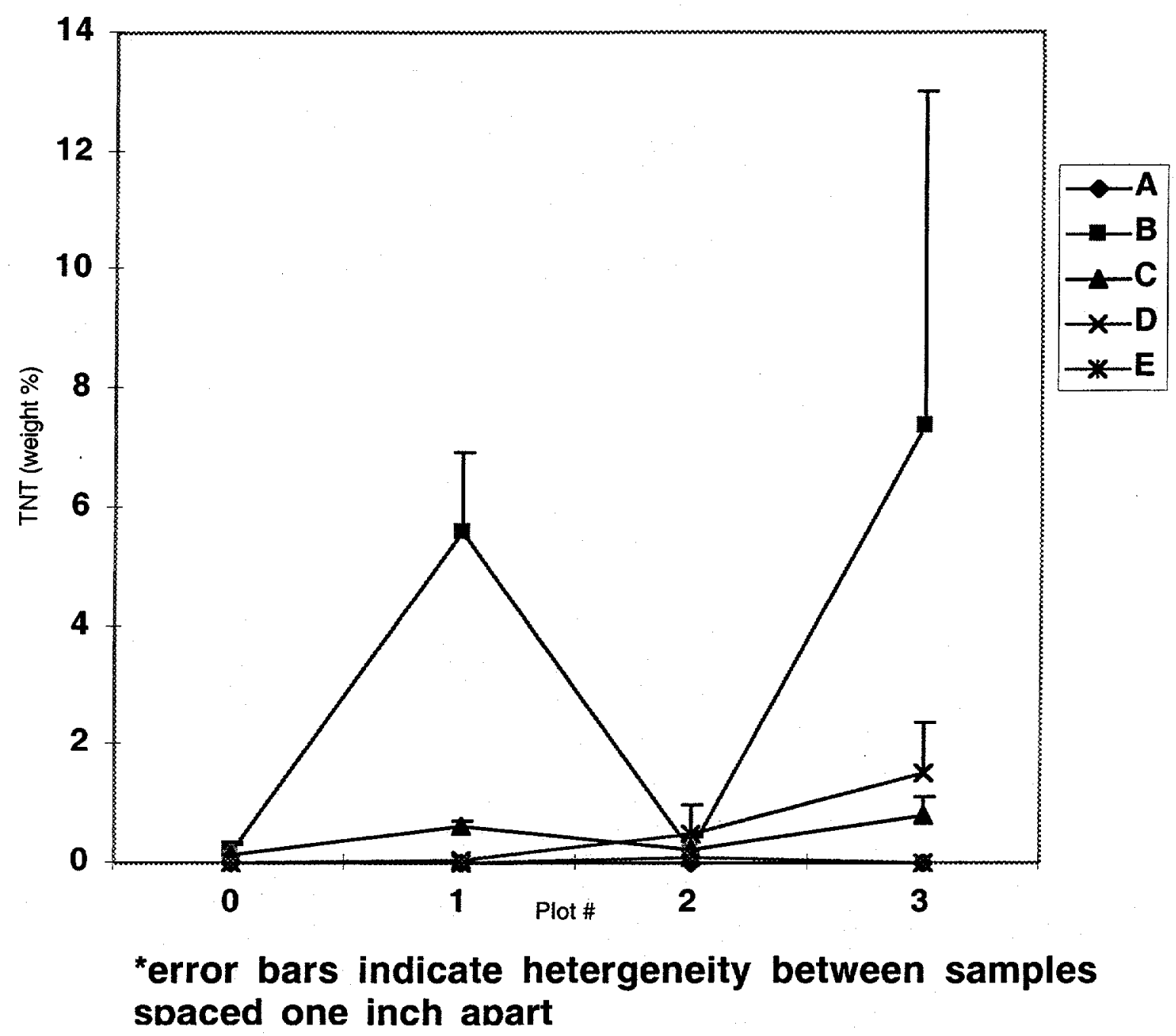

Figure 9. TNT gradient from sample matrix, plot 0 is at head of outfall, highest point, plot 3 is lowest. Samples $A$ through $E$ are approximately equidistant in a perpendicular line across the outfall.

Each of the graphs presented show some evidence of a gradient down the outfall, however, the magnitude of this gradient relative to the heterogeneity between adjacent samples is almost insignificant by comparison and would not be important as a basis for adjusting the proposed experimental remediation scheme. The most significant trend that is evident from the 3-dimensional graphs of the analytical results (Figures 4-6) appears to be a higher level of all three $\mathrm{HE}$ compounds toward the middle of the channel, as would be expected. 


\section{Potential Effects of the "Chunks"}

It was originally thought that the "chunks" found in 6 of the samples we took might make it difficult, if not impossible, to remediate the site biologically, as the highly consolidated material would be expected to be extremely slow to dissolve, even with a significant reduction of the surrounding $\mathrm{HE}$ concentration during the biodegradation process. Given that the analysis of this consolidated material showed equivalent $\mathrm{HE}$ concentrations to the surrounding material, this conclusion is not valid. There may be several explanations for this apparent contradiction. It is possible that the consolidated material was originally "chunks" of HE, but the length of time they have been resident in the outfall has been adequate to leach the HE material out, leaving the less-soluble binder behind. A second possibility is that the "chunks" represent blanks that are used routinely in the HE weapons program, but contain no $\mathrm{HE}$ component, therefore could readily be disposed of directly to the outfall in a safe manner by knowledge of process. There are probably other possibilities, but the fact remains that the "chunks" that were found in our investigation represent no major detriment to the success of a bioremediation effort. We cannot rule out the possibility of the presence of other "chunks" that do contain consolidated HE, therefore, any remedial method will require great care to avoid the possibility of initiating an explosion.

\section{Potential for Success of Bioremediation Method}

Our results show that the outfall is heavily contaminated, in some cases as much as 35 weight \% HMX, with a total HE greater than $50 \%$. However, the solubility of these compounds in the groundwater is relatively low, and the microbial community present in the outfall area is only susceptible to soluble (or bioavailable) HE. Much of the solubilized material may be quickly immobilized by organic matter present in the soil horizon, so the concentrations actually "seen" by the microorganisms are probably small. The contamination is also extremely heterogeneous, with large areas that contain little or no $\mathrm{HE}$. These areas are presumably well populated with viable organisms that could provide a microbial source in our bioremediation scheme. Additionally, the microbial community has had a long time to adapt to the presence of these toxic materials, and any surviving organisms are likely to be resistant to the toxicity of the HE because they have developed enzymatic systems that allow them to quickly degrade or otherwise detoxify these compounds, and perhaps even allow them to utilize the carbon and nitrogen present in the compounds for energy and growth. However, few species have been isolated (although that doesn't mean that they don't exist, but are only non-culturable by current methods) that are capable of using these compounds in this manner, most rely on a co-metabolic process using a different carbon source. Our bioremediation strategy is to provide this carbon source to the natural population, a strategy that we feel would be successful at remediating the site in a nonintrusive and cost-effective manner.

\section{Toxicity of HE Compounds}

The toxicity test that we used is a newly developed, patented method for toxicity testing. We selected it because of the simplicity and ease of use of the method, and because it uses bacteria as the test organism. Our concern with the toxicity of the contaminants has to do with whether they will be toxic to microorganisms (i.e. bacteria) that are involved in the bioremediation process, so this test system had greater relevance to those concerns than a system that uses a eucaryotic species as the test organism. We had hoped to correlate this method to the Microtox ${ }^{\mathrm{TM}}$ system which also uses a bacterial test organism, but this was not possible. In general, it appears that the solubility of the HE compounds in the groundwater 
will limit the amount of $\mathrm{HE}$ that is bioavailable (i.e. soluble), and as a result, will limit the toxicity of the contaminants. Our preliminary results show that, in general, these compounds do not significantly inhibit the bacteria in the test until concentrations in excess of the groundwater solubility limits are reached. However, more data is necessary before reasonable conclusions can be drawn from this preliminary research. The presence of soil will help mitigate toxicity as well, something that must be taken into consideration when assessing this complex problem. The RTCA method holds great promise for use with other similar bioremediation projects.

\section{CONCLUSIONS}

Our initial study of the HE outfall behind building 260 at TA-16 has provided a great deal of data to the ER program in order to determine the most effective remediation scheme for the site. We have shown the outfall to be highly contaminated and of great concern as a safety hazard for site workers. The potential of an explosion cannot be ignored, whatever method is chosen for remediation. The best possible method would involve minimal disturbance of the soil; therefore, we feel that in situ bioremediation would be the best candidate at this point. We have shown that the concentrations of HE in the "chunks" are similar to those in the surrounding, unconsolidated soils; therefore, not a major issue with regard to dissolution rates and their effect on bioremediation. We have not ruled out the presence of actual consolidated chunk explosive, however, and this should be considered as a potential hazard in any remediation scenario. We have shown that the contamination is extremely heterogeneous, with a wide variance between samples taken within inches of each other. This is likely to make determination of the success of clean-up extremely difficult and sample-intensive. We have only sampled to a depth of four inches, so we have limited knowledge of the levels and heterogeneity of the contamination below this level. The original scheme for this research project involved remediating from the surface down, with removal of successive layers of soil as each was remediated. This scheme would involve several years of bioremedial treatment before the explosion hazard at the site could be significantly reduced; however, the time and cost involved in such a scheme could be quite minimal. The potential hazard that exists in trying to remediate the site by excavation remains very real, and our data shows it to be even greater than was originally thought when we began the investigation.

\section{ACKNOWLEDGEMENTS}

We would like to thank Dr. James Botsford of New Mexico State University, Las Cruces, New Mexico, and his students Jeffrey Rivera and Michael Fijardo for their contributions to this project. Dr. Botsford holds the patent (U.S. patent number 5792622) on the RTCA toxicity assay system used to assess the toxicity of the high explosive compounds in this study.

\section{REFERENCES}

Binks, P.R., S. Nicklin and N.C. Bruce, 1995, Degradation of Hexahydro-1,3,5-Trinitro1,3,5-Triazine (RDX) by Stenotrophomonas maltophilia PB1, Appl. Environ. Microbiol. 61(4):1318-1322.

Botsford, J.L., 1998, A Simple Assay for Toxic Chemicals using a Bacterial Indicator, World J. Microbiol. Biotechnol. 14:369-376. 
Botsford, J.L., 1998, A Comparison of a Method to Assay Toxic Chemicals using Bacteria with More Familiar Techniques, Alternatives to Lab. Animals, submitted.

Bruhn, C., H. Lenke and H.-J. Knackmuss, 1987, Nitrosubstituted Aromatic Compounds as Nitrogen Source for Bacteria, Appl. Environ. Microbiol. 53:208-210.

Bryant, C. and M. DeLuca, 1991, Purification and Characterization of an OxygenInsensitive $\mathrm{NAD}(\mathrm{P}) \mathrm{H}$ Nitroreductase from Enterbacter cloacae, J. Biol. Chem. 266(7):4119-4125.

Delgado, A., M.G. Wubbolts, M.A. Abril and J.L. Ramos, 1992, Nitroaromatics are Substrates for the TOL Plasmid Upper Pathway Enzymes, Appl. Environ. Microbiol. $58(1): 415-417$.

Funk, S.B., D.J. Roberts, D.L. Crawford and R.L. Crawford, 1993, Initial-Phase Optimization for Bioremediation of Munition Compound-Contaminated Soils, Appl. Environ. Microbiol. 59(7):2171-2177.

Harrigan, W.F., 1976, In Laboratory Methods in Food and Dairy Microbiology, Academic Press, NY. Harcourt, Brace and Jovanovich publishers, pp. 383-389.

Kinouchi T. and Ohnishi, Y., 1983, Purification and Characterization of 1-Nitropyrene Nitroreductases from Bacteroides fragilis, Appl. Environ. Microbiol. 46(3):596-604.

Los Alamos National Laboratory, 1996, RFI Report for Potential Release Sites in TA-16, Environmental Restoration Project, Los Alamos National Laboratory, LA-UR-96-3191.

McCarthy, C.M. and L. Murray, 1996, Viability and Metabolic Features of Bacteria Indigenous to a Contaminated Deep Aquifer, Microb. Ecol. 32: 305-321.

McCormick, N.G., F.E. Feeherry and H.S. Levinson, 1976, Microbial Transformation of 2,4,6-Trinitrotoluene and Other Nitroaromatic Compounds, Appl. Environ. Microbiol. 31(6):949-958.

Schackmann, A. and R. Müller, 1991, Reduction of Nitroaromatic Compounds by Different Pseudomonas species under Aerobic Conditions, Appl. Microbiol. Biotechnol. 34:809-813.

Spain, J.C., O. Wyss, and D.T. Gibson, 1979, Enzymatic Oxidation of Para-Nitrophenol, Biochem. Biophys. Res. Comm. 88(2):634-641.

Spiker, J.K., D.L. Crawford and R.L. Crawford, 1992, Influence of 2,4,6-Trinitrotoluene (TNT) Concentration on the Degradation of TNT in Explosive-Contaminated Soils by the White Rot Fungus Phanerochaete chrysosporium, Appl. Environ. Microbiol. 58(9):31993202.

Stahl, J.D. and S.D. Aust, 1993a, Plasma-Membrane Dependent Reduction of 2,4,6Trinitrotoluene by Phanerochaete chrysosporium, Biochem. Biophys. Res. Comm. 192(2):471-476.

Stahl, J.D. and S.D. Aust, 1993b, Metabolism and Detoxification of TNT by Phanerochaete chrysosporium, Biochem. Biophys. Res. Comm. 192(2):477-482. 
Sublette, K.L., E.V. Ganapathy and S. Schwartz, 1992, Degradation of Munition Wastes by Phanerochaete chrysosporium, Appl. Biochem. Biotech. 34/35:709-723.

Tiedje, J.M., 1982, Denitrification, In Methods of Soil Analysis, Part 2: Chemical and Microbiological Properties, ASA-SSSA, Madison, WI, pp. 1011-1026.

U. S. Environmental Protection Agency, 1995, Office of Research and Development. Innovative Technology Evaluation Report: JR Simplot Ex-Situ Bioremediation Technology for Treatment of Dinoseb-Contaminated Soils, U. S. Government Printing Office, Washington, D.C., EPA /540/R-94/508.

U.S. Environmental Protection Agency, 1993, Treatment Technologies for Explosive Waste: Approaches for the Remediation of Federal Facility Sites Contaminated with Explosive or Radioactive Waste, EPA/625/R-93/0132.

Valli, K., B.J. Brock, D.K. Joshi and M.H. Gold, 1992, Degradation of 2,4Dinitrotoluene by the Lignin-Degrading Fungus Phanerochaete chrysosporium, Appl. Environ. Microbiol. 58(1):221-228.

Vorbeck, C., H. Lenke, P. Fischer and H.-J. Knackmuss, 1994, Identification of a Hydride-Meisenheimer Complex as a Metabolite of 2,4,6-Trinitrotoluene by a Mycobacterium Strain, J. Bacteriol. 176(3):932-934.

Young, D.M., J.L. Hanners, K.L. Ogden and P.J. Unkefer, 1994, In situ Remediation of RDX and HMX Contaminated Soil: A Feasibility Study for Remediating the Outfall of Building 260 at TA-16, Los Alamos National Laboratory, LANL ER Report, unpublished.

Yu, W., W.K. Dodds, M.K. Banks, J. Skalsky and E.A. Strauss, 1995, Optimal Staining and Sample Storage Time for Direct Microscopic Enumeration of Total and Active Bacteria in Soil with Two Fluorescent Dyes, Appl. Environ. Microbiol. 61: 3367-3372.

Zeyer, J. and P.C. Kearney, 1984, Degradation of $o$-Nitrophenol and $m$-Nitrophenol by Pseudomonas putida, J. Agric. Food Chem. 32:238-242. 